\title{
APLIKASI JENJANG KARIR PEGAWAI DI PT BITA ENARCON ENGINEERING BANDUNG
}

\author{
Randy Agustian Kusuma ${ }^{1}$,Linda Salma Angreani ${ }^{2}$ \\ ${ }^{1}$ Jurusan Teknik Informatika Fakultas Teknik Dan Ilmu Komputer Universitas \\ Komputer Indonesia,Jl. Dipati Ukur No. 112-116, Bandung 40132,Email \\ :randyagustian@gmail.com \\ 2 Jurusan Teknik Informatika Fakultas Sains dan Teknologi, Universitas Islam Negeri \\ Malang, \\ J1. Gajayana no 50, Malang65144,Email: lindasalma@gmail.com
}

\begin{abstract}
Abstrak-PT. Bita Enarcon Engineering adalah perusahaan konsultan yang menyediakan jasa perencanaan studi dan konsultasi untuk berbagai pembangunan dan pekerjaan konstruksi, perusahaan ini juga melayani pelayanan umum sebagai pelayanan pendukung, akan tetapi perusahaan ini memiliki suatu permasalahan dalam pengelolaan kepegawaian khususnya penyeleksian pegawai baru untuk menempati posisi jabatan tertentu dan proses pengangkatan golongan pegawai masih dilakukan secara manual, sehingga dalam penempatan pegawai baru sering mengalami ketidaksesuaian antara pendidikan, pengalaman dalam bekerja, dan perilaku yang dimiliki oleh pegawai baru dengan suatu jabatan yang akan diposisikan oleh perusahaan. Maka perusahaan ini membutuhkan sebuah aplikasi yang dapat memudahkan untuk proses penyeleksian pegawai baru untuk menempati posisi jabatan tertentu dan proses pengangkatan golongan pegawai. Metode analisis yang digunakan dalam pembangunan sistem ini adalah berdasarkan metode terstruktur, dimana tools yang digunakan untuk memodelkan aliran data adalah DFD (Data Flow Diagram), diagram untuk memodelkan relasi antar data adalah diagram E-R. Aplikasi ini terdiri dari beberapa hak akses yaitu hak akses sebagai admin oleh manager divisi admin personalia dan umum dan hak akses sebagai petugas oleh staf bid/urs admin dan personalia. Aplikasi jenjang karir pegawai di PT. Bita Enarcon Enginnerring Bandung ini mempunyai kelebihan yaitu aplikasi dapat memberikan kemudahan dalam mengelola data pegawai, dapat menghindari kesalahan dalam mengelola kenaikan golongan pegawai, dapat meminimalisir kemungkinan data hilang, dan dapat menempatkan jabatan pegawai baru secara objektif sesuai dengan pendidikan, pengalaman dalam bekerja, dan perilaku pegawai baru yang diperlukan oleh suatu jabatan tertentu.
\end{abstract}

Kata kunci : Jenjang karir, seleksi pegawai, pengangkatan golongan, DFD, E-R, Manager dan staf divisi admin personalia.

\section{PENDAHULUAN}

PT. Bita Enarcon Engineering adalah perusahaan konsultan yang berada di Kota Bandung dan telah memberikan kontribusi keahlian selama beberapa tahun terakhir ini. Selain untuk menyediakan jasa perencanaan studi dan konsultasi untuk berbagai pembangunan dan pekerjaan konstruksi, perusahaan ini juga melayani pelayanan umum sebagai pelayanan pendukung, akan tetapi perusahaan ini memiliki suatu permasalahan dalam pengelolaan kepegawaian khususnya penyeleksian pegawai baru untuk menempati posisi jabatan tertentu dan proses pengangkatan golongan pegawai masih dilakukan secara manual, sehingga dalam penempatan pegawai baru sering mengalami ketidaksesuaian antara pendidikan, pengalaman dalam bekerja, dan perilaku yang dimiliki oleh pegawai 
baru dengan suatu jabatan yang akan diposisikan oleh perusahaan.

Hal tesebut dapat terjadi karena ada kemungkinan penilaian bersifat subjektif terhadap seseorang sehingga proses tidak berjalan dengan semestinya dan hasil yang dicapai kemungkinan tidak sesuai dengan target. Selain itu dalam pengangkatan golongan pegawai sering terjadi kesalahan dalam kenaikan golongan, sehingga menyulitkan pihak perusahaan dalam menentukan pegawai yang akan mendapatkan kenaikan golongan disetiap jabatan.

Berdasarkan permasalahan diatas maka perusahaan ini membutuhkan sebuah aplikasi yang dapat memudahkan untuk proses penyeleksian pegawai baru untuk menempati posisi jabatan tertentu dan proses pengangkatan golongan pegawai dengan tidak bergantung lagi kepada lembaran-lembaran data pegawai dan membantu menganalisis para pegawai baru yang sesuai dengan kriteria suatu jabatan tertentu.

Metode yang sesuai untuk mengatasi proses penyeleksian pegawai baru yaitu menggunakan metode profile matching, yang merupakan proses membandingkan antara kompetensi individu kedalam kompetensi jabatan sehingga dapat diketahui perbedaan kompetensinya (gap), semakin kecil gap yang dihasilkan maka bobot nilainya semakin besar yang berarti memiliki peluang lebih besar untuk pegawai menempati posisi jabatan tersebut. Berdasarkan latar belakang yang telah disebutkan diatas, maka di dapat permasalahan yang ada sebagai berikut :

1. Bagaimana cara mengelola data pegawai agar mudah digunakan dan mudah dipahami oleh penggunannya.

2. Bagaimana menghasilkan laporan data pegawai sesuai kebutuhan yang diinginkan.

3. Bagaimana menempatkan pegawai baru sesuai dengan kriteria yang diinginkan oleh suatu jabatan.
4. Bagaimana mengelola data pegawai yang akan mendapatkan kenaikan golongan pegawai.

5. Bagaimana membangun Aplikasi Jenjang Karir Pegawai Di PT. Bita Enarcon Engineering Bandung.

Berdasarkan permasalahan yang diteliti, maka maksud dari penelitian ini adalah untuk membangun aplikasi yang nantinya akan menjadi alat pengolahan data pegawai di PT. Bita Enarcon Engineering Bandung.

Sedangkan tujuan yang akan dicapai dalam penelitian ini adalah :

1. Menganalisis sistem yang telah ada dan mengembangkan sistem tersebut jika dibutuhkan.

2. Memberikan kemudahan dalam mengelola data pegawai.

3. Menghindari kesalahan dalam mengelola kenaikan golongan pegawai.

4. Meminimalisir kemungkinan data hilang.

5. Memberikan kemudahan dalam memperoleh informasi berupa laporan dengan cepat, tepat dan akurat.

6. Menempatkan jabatan pegawai baru secara objektif sesuai dengan pendidikan, pengalaman dalam bekerja, dan perilaku pegawai baru yang diperlukan oleh suatu jabatan tertentu.

Pembuatan perangkat lunak pengolahan data ini memiliki batasan masalah/ruang lingkup kajian sebagai berikut :

1. Aplikasi pengolahan data ini hanya digunakan di lingkungan PT. Bita Enarcon Engineering Bandung.

2. Aplikasi ini dibangun khusus untuk menyeleksi pegawai baru untuk menempati posisi jabatan tertentu dan proses pengangkatan golongan pegawai yang dilakukan pada bagian administrasi personalia dan umum pada PT. Bita Enarcon Engineering Bandung. Created with 
3. Aplikasi ini hanya mengolah data sebagai berikut :

a. Pengolahan data master terdiri dari pengolahan data pegawai, pengolahan data divisi, pengolahan data jabatan, dan pengolahan data golongan.

b. Pengolahan data seleksi terdiri dari pengolahan data calon pegawai, pengolahan data profile calon pegawai, pengolahan data profile jabatan, pengolahan data core faktor dan pengolahan data penilaian.

c. Pengolahan data kenaikan terdiri dari pengolahan data profile pegawai, pengolahan data kenaikan dan pengolahan data penilaian pegawai.

d. Pengolahan data laporan terdiri dari laporan data pegawai, laporan data calon pegawai, laporan data penilaian pegawai, dan laporan data penilaian calon pegawai.

e. Pengolahan data user.

4. Metode yang digunakan pada penilaian pegawai baru untuk jabatan tertentu yaitu metode profile matching yang terdiri dari penilaian pegawai terhadap kapasitas intelektual, sikap kerja dan perilaku.

5. Fasilitas yang dapat digunakan oleh user dalam aplikasi ini adalah sebagai berikut :

a. loginuser terdiri dari login petugas dan login admin.

b. Pengolahan data pegawai meliputi pilih data pegawai, tambah data pegawai, edit data pegawai, pencarian data pegawai, pengurutan data pegawai dan refresh data pegawai.

c. Pengolahan data divisi meliputi pilih data divisi, tambah data divisi, dan edit data divisi.

d. Pengolahan data jabatan meliputi pilih data jabatan, tambah data jabatan, dan edit data jabatan. e. Pengolahan data golongan meliputi pilih data golongan, tambah data golongan, dan edit data golongan.

f. Pengolahan data calon pegawai meliputi pilih data calon pegawai, tambah data calon pegawai, edit data calon pegawai, pencarian data calon pegawai, pengurutan data calon pegawai dan refresh data calon pegawai.

g. Pengolahan data profile calon pegawai meliputi pilih data profile calon pegawai, tambah data profile calon pegawai, edit data profile calon pegawai.

h. Pengolahan data profile jabatan meliputi pilih data profile jabatan, tambah data profile jabatan, edit data profile jabatan.

i. Pengolahan data core faktor meliputi tambah data core faktor dan edit data core faktor.

j. Pengolahan data penilaian meliputi proses hitung, bobot, total dan ranking pegawai.

k. Pengolahan data profile pegawai meliputi pilih data profile pegawai, tambah data profile pegawai, edit data profile pegawai

1. Pengolahan data kenaikan golongan pegawai meliputi tambah data kenaikan golongan pegawai, dan edit kenaikan golongan pegawai.

$m$. Pengolahan data user meliputi tambah data user, dan edit data user.

6. Aplikasi jenjang karir pegawai di PT. Bita Enarcon Engneering Bandung ini berbasis client server.

7. Metode analisis yang digunakan dalam pembangunan sistem ini berdasarkan data terstruktur yaitu menggunakan Flowmap, Entity Relationalship Diagram (ERD), dan untuk menggambarkan diagram proses yang menggunakan Data Flow Diagram (DFD).

8. Perangkat lunak yang digunakan untuk membangun aplikasi ini adalah 
Borland Delphi 7 sedangkan MySQL digunakan sebagai database.

\section{MODEL, ANALISIS, DESAIN, DAN IMPLEMENTASI}

\subsection{Model}

Teknik analisis data dalam pembuatan perangkat lunak yang dibangun ini menggunakan paradigma perangkat lunak secara waterfall, sepeti analysis, design, coding, testing, dan maintenance.

Tahap-tahap pengembangan perangkat lunak metode waterfall dapat dilihat pada gambar :

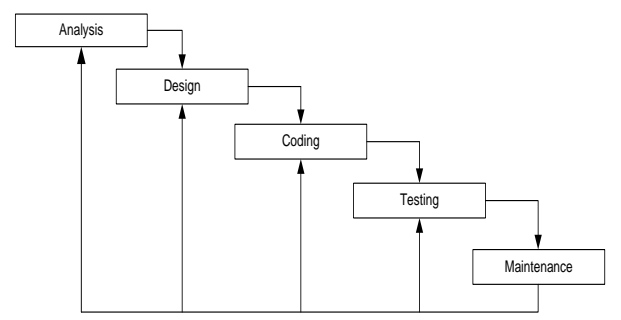

\section{Gambar 1 Metode The Classic Life Cycle / Waterfall}

a. Analysis adalah tahap menganalisis hal-hal yang diperlukan dalam pelaksanaan pembuatan perangkat lunak agar sesuai dengan kebutuhan.

b. Design adalah proses yang menterjemahkan syaratatau kebutuhan ke dalam sebuah representasi software yang dapat diperkirakan demi kualitas sebelum dimulai pemunculan kode sehingga dapat dimenegerti oleh user.

c. Coding adalah tahap menterjemahkan data yang telah dirancang kedalam bahasa pemograman tertentu.

d. Testing adalah proses pengujian berfokus pada logika internal software, memastikan bahwa semua pernyataan sudah diuji, dan pada eksternal fungsional, yaitu mengarahkan pengujian untuk menemukan kesalahan - kesalahan dan memastikan bahwa input yang dibatasi akan memberikan hasil aktual yang sesuai dengan hasil kebutuhan e. Maintenance adalah Tahap dimana suatu perangkat lunak yang sudah selesai dapat mengalami perubahanpermintaan user.

\subsection{ANALISIS}

\subsubsection{Analisis Prosedur yang sedang berjalan}

Bagan alir dokumen atau disebut juga dengan bagan alir formulir merupakan bagan alir yang menunjukan arus dari dokumen formulir. Berdasarkan analisis di atas maka terdapat prosedur yang berjalan pada aplikasi jenjang karir pegawai di PT. Bita Enarcon Engineering Bandung. Adapun prosedur yang ada pada sistem tersebut yaitu prosedur seleksi pegawai baru, prosedur pengajuan pegawai baru, dan prosedur kenaikan golongan pegawai.

\subsubsection{Analisis Basis Data}

Dalam memodelkan data dan hubungan-hubungan data yang ada di dalam aplikasi jenjang karir pegawai dapat digunakan alat bantu yaitu diagram E-R, dimana terdapat kunci yang unik (primary key) pada setiap entitas (tabel induk) yang dapat membedakan dengan atribut lainnya sehingga tabel tersebut dapat dijadikan referensi untuk tabel yang lainnnya. Gambar dibawah menggambarkan bagaimana relasi antar entitas yang saling berhubungan pada aplikasi jenjang karir pegawai yang akan dibangun pada PT. Bita Enarcon Engineering Bandung.

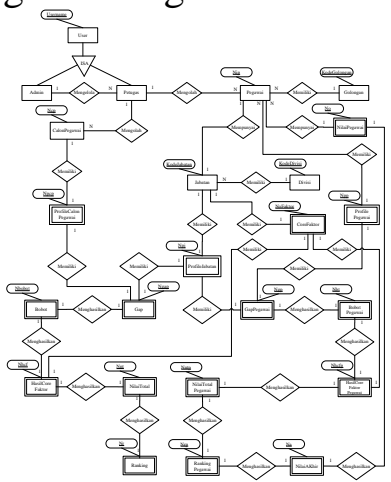

Gambar 2. ERD 


\subsubsection{Analisis Kebutuhan Fungsional 2.2.4 Diagram Konteks}

Diagram konteks merupakan pola penggambaran yang berfungsi untuk memperlihatkan interaksi tersebut dengan lingkungan dimana sistem tersebut ditempatkan. Dalam diagram konteks, sistem dianggap sebuah objek yang tidak dijelaskan secara rinci karena yang ditekankan adalah interaksi sistem dengan lingkungan yang akan mengaksesnya. Berikut merupakan diagram konteks pada aplikasi jenjang karir pegawai di PT. Bita Enarcon Engineering Bandung.

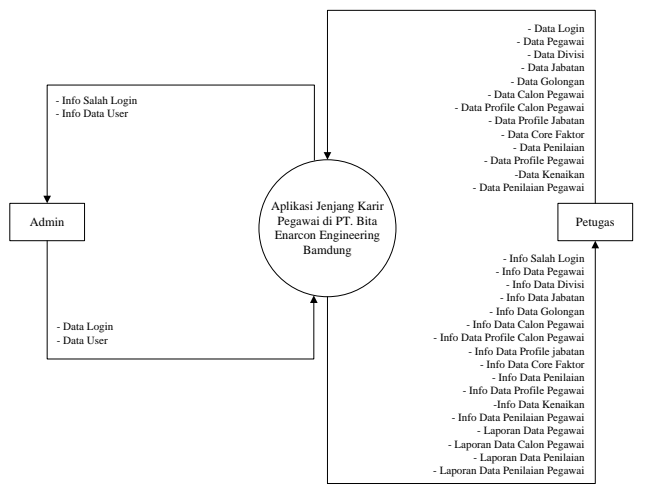

.Gambar 3. Diagram Konteks

\subsubsection{Data Flow Diagram}

Data flow diagram digunakan untuk menggambarkan sistem secara lebih detail yang ada pada diagram konteks menjadi beberapa proses yang terjadi antara entitas yang terlibat dalam aplikasi jenjang karir pegawai ini.

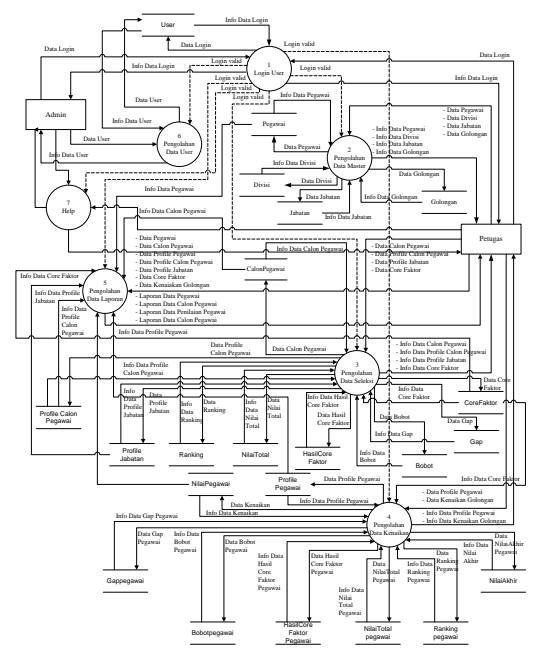

Gambar 4. DFD level 1

\subsubsection{Diagram Relasi}

Untuk lebih mudah dalam merancang sistem, maka dibuat suatu diagram yang menggambarkan hubungan antar file dimana field kunci dan field tamu yang saling berhubungan. Adapun diagram skema relasi atau relasi file dari rancangan sistem ini dapat digambarkan sebagai berikut :

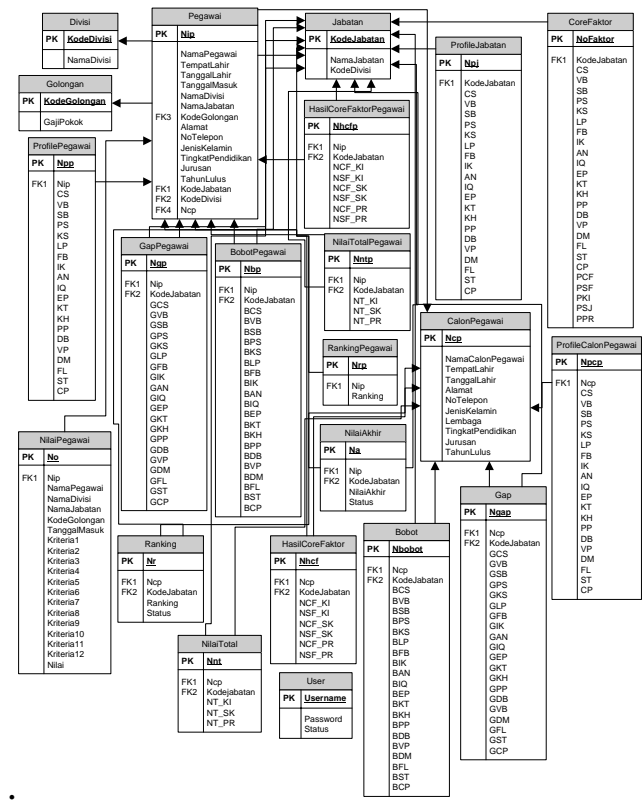

Gambar 5. Diagram Relasi

\subsubsection{Desain}

Desain Struktur menu dirancang sesuai dengan level pengguna sistem. Terdapat duapengguna aplikasi ini yaitu admin danpetugas. Adapun Struktur menunya adalah sebagai berikut :

\subsubsection{Struktur MenuPetugas}

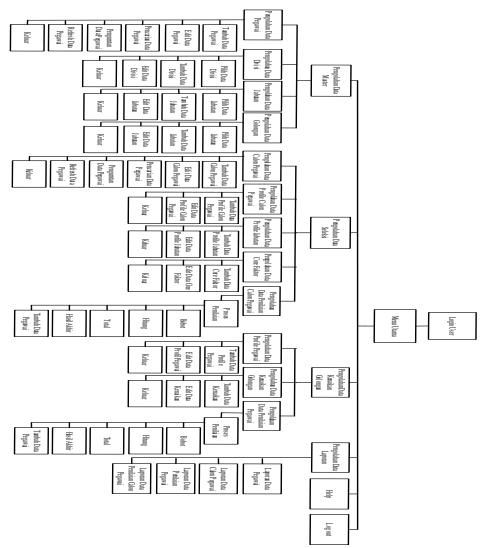

Gambar 6. Struktur MenuPetugas 


\subsubsection{Struktur Menu Admin}

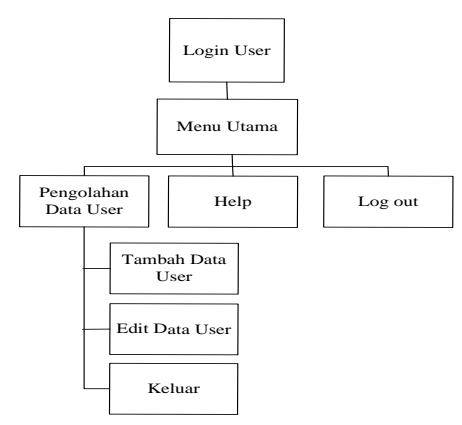

Gambar 8. Struktur Menu Admin

\subsection{Implementasi}

Tahap implementasi merupakan tahap penciptaan perangkat lunak, tahap kelanjutan dari kegiatan perancangan sistem. Tahap ini merupakan tahap dimana sistem siap untuk dioperasikan, yang terdiri dari penjelesan mengenai lingkungan implementasi, dan implementasi program.

\subsection{Perangkat Keras Pembangun}

Perangkat keras yang ada saat ini di ruang kerja PT. Bita Enarcon Engineering (BEE) Bandung sudah memenuhi standard untuk menjalankan aplikasi sistem yang dibangun. Adapun spesifikasinya sebagai berikut :

Tabel 1. Perangkat Keras Pembangun

\begin{tabular}{|c|c|c|}
\hline No. & $\begin{array}{c}\text { Perangkat } \\
\text { Keras }\end{array}$ & Existensi \\
\hline 1. & Processor & $\begin{array}{c}\text { Intel Pentium III } \\
2,2 \mathrm{GHz}\end{array}$ \\
\hline 2. & RAM & $512 \mathrm{MB}$ \\
\hline 3. & VGA & $\begin{array}{c}\text { GeForce MX } \\
4400,64 \mathrm{MB}\end{array}$ \\
\hline 4. & Hardisk & $40 \mathrm{~GB}$ \\
\hline 5. & CD-ROM & - \\
\hline 6. & Monitor & 14 \\
\hline 7. & $\begin{array}{c}\text { Keyboard dan } \\
\text { mouse }\end{array}$ & Standar USA \\
\hline
\end{tabular}

\subsubsection{Perangkat Keras Minimum}

Perangkatkeras minimum yang dibutuhkanuntukpengembangandanpengo perasiansistem yang dibangun memiliki spesifikasi pada tabel dibawahini.

Tabel 2. Perangkat Keras Minimun

\begin{tabular}{|l|l|l|}
\hline No. & $\begin{array}{l}\text { Perangkat } \\
\text { Keras }\end{array}$ & $\begin{array}{l}\text { Spesifikasi } \\
\text { Minimum }\end{array}$ \\
\hline 1. & Processor & $\begin{array}{l}\text { Intel Pentium II } \\
450 \mathrm{MHz}\end{array}$ \\
\hline 2. & RAM & $256 \mathrm{MB}$ \\
\hline 3. & VGA & SVGA \\
\hline 4. & Hardisk & $40 \mathrm{~GB}$ \\
\hline 5. & CD-ROM & - \\
\hline 6. & Monitor & 7,5, \\
\hline 7. & $\begin{array}{l}\text { Keyboard dan } \\
\text { mouse }\end{array}$ & Standar USA \\
\hline
\end{tabular}

\subsubsection{Perangkat Lunak Pembangun}

Sistem operasi yang digunakan di PT. Bita Enarcon Engineering adalah Windows XP SP 2 sehingga sudah sangat mencukupi untuk dapat menjalankan perangkat lunak yang akan dibangun. Adapun kebutuhan minimal perangkat lunak yang dibutuhkan dalam pembangunan aplikasi ini adalah sebagai berikut :

Tabel 3. Perangkat Lunak Pembangun

\begin{tabular}{|l|l|}
\hline $\begin{array}{l}\text { Perangkat } \\
\text { Kunak }\end{array}$ & Keterangan \\
\hline $\begin{array}{l}\text { Windows XP SP } \\
\text { Borland Delphi 7 }\end{array}$ & $\begin{array}{l}\text { Tool pembangun } \\
\text { aplikasi }\end{array}$ \\
\hline Pascal & $\begin{array}{l}\text { Bahasa } \\
\text { pemrograman } \\
\text { yang digunakan }\end{array}$ \\
\hline MySQL & DBMS \\
\hline
\end{tabular}

\subsubsection{Perangkat Lunak Minimum}

Perangkatlunak minimum yang dibutuhkanuntukpengembangandanpengo 
perasiansistem yang dibangun memiliki spesifikasi pada tabel dibawahini.

Tabel 4. Perangkat Lunak Minimum

\begin{tabular}{|c|c|}
\hline $\begin{array}{c}\text { Perangkat } \\
\text { Lunak }\end{array}$ & Keterangan \\
\hline $\begin{array}{c}\text { Windows XP SP } \\
2\end{array}$ & Sistem operasi \\
\hline Borland Delphi 7 & $\begin{array}{c}\text { Tool pembangun } \\
\text { aplikasi }\end{array}$ \\
\hline Pascal & $\begin{array}{c}\text { Bahasa } \\
\text { pemrograman } \\
\text { yang digunakan }\end{array}$ \\
\hline MySQL & DBMS \\
\hline
\end{tabular}

\subsection{Pengujian}

Pengujian yang dilakukan yaitu pengujian secara fungsional (alpha) dan betha. Metode yang digunakan dalam pengujian ini adalah pengujian black box yang berfokus pada persyaratan fungsional dari sistem yang dibangun. Rencana pengujian sistem dibedakan berdasarkan fungsional pengguna yang akan menggunakan aplikasi ini

\subsubsection{Kesimpulan Hasil Pengujian Alpha}

Berdasarkan hasil pengujian dengan kasus sample uji yang telah dilakukan memberikan kesimpulan bahwa pada proses masih memungkinkan untuk terjadinya kesalahan pada sintaks karena penyaringan proses dalam bentuk arahan tampilan message box belum maksimal diciptakan dan ditampilkan, tetapi secara fungsional sistem sudah dapat menghasilkan output yang diharapkan.

\subsubsection{Kesimpulan Hasil Pengujian Betha}

Berdasarkan pengujian yang dilakukan yaitu pengujian Betha dapat ditarik kesimpulan bahwa aplikasi jenjang jarir pegawai di PT. Bita Enarcon Engineering Bandung yang dibuat ini mempunyai kelebihan, yaitu aplikasi mudah digunakan, aplikasi mampu meminimalisir kemungkinan data hilang, aplikasi memudahkan dalam pengolahan data pegawai, data divisi, data jabatan, data golongan, data calon pegawai, data profile pegawai, data profile calon pegawai, data profile jabatan, dan data core faktor, aplikasi sudah membantu menempatkan jabatan pegawai baru secara objektif sesuai dengan pendidikan, pengalaman dalam bekerja, dan perilaku dan informasi berupa laporan yang dihasilkan aplikasi sudah cepat, tepat dan akurat.

\section{HASIL DISKUSI}

Dari analisa dan perancangan yang telah dilakukan, dapa ditarik kesimpuan yaitu

1. Dengan kata lain bahwa pembangunan sistem ini mengurangi pengguna dari kesalahan dalam menggunakan sistem dan secara fungsional mengeluarkan hasil yang sesuai dengan apa yang diharapkan

2. Aplikasi jenjang karir pegawai ini dinilai mudah untuk digunakan dan dapat dipelajari,serta memberikan kemudahan kepada pengguna untuk mendapatkan informasi, dan membantu pihak perusahaan untuk menyeleksi pegawainya.

\section{KESIMPULAN DAN SARAN}

\subsection{Kesimpulan}

Berdasarkan hasil analisis yang didapat dalam pengujian alpha maupun betha, serta disesuaikan dengan tujuan awal skripsi ini, maka diperoleh kesimpulan sebagai berikut :

1. Aplikasi yang dibuat dapat memberikan kemudahan dalam mengelola data pegawai.

2. Aplikasi dapat menghindari kesalahan dalam mengelola kenaikan golongan pegawai. 
3. Aplikasi yang dibuat dapat meminimalisir kemungkinan data hilang.

4. Aplikasi dapat memberikan kemudahan dalam memperoleh informasi berupa laporan dengan cepat, tepat dan akurat.

5. Aplikasi yang dibangun dapat menempatkan jabatan pegawai baru secara objektif sesuai dengan pendidikan, pengalaman dalam bekerja, dan perilaku pegawai baru yang diperlukan oleh suatu jabatan tertentu.

\subsection{Saran}

Aplikasi jenjang karir pegawai ini masih dapat dikembangkan seiring dengan berkembangnya spesifikasi kebutuhan pengguna, sistem yang harus dipenuhi dalam mencapai hasil dan kinerja sistem yang kebih baik dikarenakan selain mempunyai kelebihan tentunya aplikasi ini tidak lepas dari kelemahan, sehingga kelemahan tersebut dapat dimasukkan kedalam saran pengembanagan perangkat lunak ini. Berikut adalah beberapa saran untuk pengembangan perangkat lunak :

1. Melakukan perawatan terhadap aplikasi yang dibangun.

2. Aplikasi jenjang karir pegawai di PT. Bita Enarcon Engineering Bandung dapat dikembangkan dengan berbasis web.

3. Aplikasi jenjang karir pegawai dapat dikembangkan dengan menambahkan aplikasi penggajian pegawai agar menjadi aplikasi yang lebih baik.

\section{DAFTAR PUSTAKA}

Kusrini. 2008. Konsep dan Aplikasi Sistem Pendukung Keputusan. Yogyakarta : Penerbit Andi.

Yakub. 2008. Sistem Basis Data Tutorial Konseptual. Yogyakarta: Penerbit Graha Ilmu.
Jogiyanto, Hartono. 2007. Pengenalan Komputer : Dasar Ilmu Komputer, Pemrograman, Sistem Informasi dan Intelegensi Buatan. Yogyakarta : Penerbit Andi.

Saiful, Kusnassriyanto. 2008. Teknik Pemrograman Delphi. Bandung : Penerbit Informatika.

Kania, Mira. Diktat Kuliah Rekayasa Perangkat Lunak (RPL), Universitas Komputer Indonesia, 2010.

Finandhita, Alif, Diktat Kuliah Pemrograman II (Teori dan Praktikum) BORLAND DELPHI, Universitas Komputer Indonesia, 2009.

Dharmayanti, Dian, Diktat Kuliah Basis Data, Universitas Komputer Indonesia, 2009.

Kania, Mira, Diktat Kuliah Interaksi Manusia dan Komputer, Universitas Komputer Indonesia, 2010. 